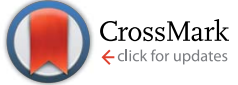

Cite this: RSC Adv., 2017, 7, 13130
Received 8th January 2017 Accepted 20th February 2017

DOI: $10.1039 / \mathrm{c} 7 \mathrm{ra00293a}$

rsc.li/rsc-advances

\section{Preparation and characterization of silicone rubber with high modulus via tension spring-type crosslinking $\dagger$}

\begin{abstract}
Linglong Feng, Shusheng Li and Shengyu Feng*
High-molecular-weight poly[(aminopropyl)methylsiloxane-co-dimethylsiloxane] (P2) and poly [(aminoethylaminopropyl)-methylsiloxane-co-dimethylsiloxane] (P3) were synthesized through base equilibration of 3-aminopropylheptamethylcyclo-tetrasiloxane or $\mathrm{N}$ - $\beta$-aminoethyl- $\boldsymbol{\gamma}$-aminopropylheptamethylcyclotetrasiloxane with octamethylcyclotetrasiloxane. These materials were crosslinked with oligo [(acryloxypropyl)methylsiloxane-co-dimethylsiloxane] (AP-PDMS) via an aza-Michael reaction to produce novel silicone rubbers. Diaddition and triaddition reactions occurred between the aminopropyl groups of P2 and the aminoethylaminopropyl groups of P3 with the acyl groups of AP-PDMS. This led to the higher modulus of novel silicone rubbers prepared via "tension spring-type crosslinking" compared with that of the silicone rubber prepared from poly[(piperazinylpropyl)methylsiloxane-co-dimethylsiloxane] (P1) via monoaddition reaction. Crosslinking mechanism was proven by solid-state ${ }^{13} \mathrm{C} N \mathrm{NR}$ and Fourier transform infrared spectroscopy. Curing characteristics were measured through cure curves conducted on rheometry. The postcure conditions and the ratio of crosslinkers used were investigated in detail. Analysis of mechanical properties showed that tension spring-type crosslinking improved the modulus of silicone rubber based on $\mathrm{P} 2$ or $\mathrm{P} 3$.
\end{abstract}

\section{Introduction}

Silicone rubber is one of the most promising materials because of its unique properties, including superior temperature and chemical resistance, weather resistance, aging resistance, electrical insulation, and biocompatibility. ${ }^{1-4}$ Silicone rubber has been widely used in many fields, such as in aviation, electrical industry, automobile manufacturing, and medical apparatus. ${ }^{5-9}$ In general, the modulus of silicone rubber is low, and a small stress in the silicone rubber immediately causes a large deformation, limiting its application to a certain extent, particularly in the dynamic circumstance. The modulus of silicone rubber can be improved by adding fillers to rubber formulations. For instance, silica is broadly used to prepare silicone rubber for its good reinforcing effect. ${ }^{10,11}$ However, the capability of silica to improve the modulus is limited. Fibers, such as fiberized blast furnace slag fibers or textile fibers, have also been used to prepare silicone rubber to good results, that is, the rubber modulus is increased. ${ }^{12,13}$ However, other mechanical properties are reduced sharply, particularly the flexibility of the silicone rubber. Another way to improve the modulus is to increase

Key Laboratory of Special Functional Aggregated Materials, Ministry of Education, School of Chemistry and Chemical Engineering, Shandong University, Jinan, 250100, People's Republic of China. E-mail: fsy@sdu.edu.cn

$\dagger$ Electronic supplementary information (ESI) available. See DOI: 10.1039/c7ra00293a the crosslinking density, but this process also decreases the elasticity, as well as other mechanical properties, of the silicone rubber. ${ }^{14,15}$ The decreased elasticity is caused by the unfixed junction or the irregular distribution of crosslinking points that leads to the low modulus of silicone rubber. Crosslinking density has to be increased to improve the modulus. However, high crosslinking density will not be beneficial to disperse the stress easily resulting in the rupture of chain segments. High crosslinking density also restricts the chain segment motion and decreases the average molecular weight between crosslinking points $\left(M_{\mathrm{c}}\right)$, thus the poor flexibility of silicone rubber. ${ }^{\mathbf{1 6}}$

The classical type of crosslinking is formed by adding crosslinking agent. The crosslinking points focus on the agent, and this is usually called concentration crosslinking or external concentration crosslinking. ${ }^{15,17}$ Given that concentration crosslinking can improve the tear strength, it is widely used in preparing common silicone rubber. Our strategy was to change the molecular structures of base gums and cure these base gums through internal concentration crosslinking, that is, more than one crosslinking points are converged on every side chain of base gums. The junction regularly focused on the main chain, which looks like tension spring, of base gums. Thus, we called it "tension spring-type crosslinking". This crosslinking would not decrease $M_{\mathrm{c}}$ when the crosslinking density is increased, and the stress could be easily dispersed. Thus, the modulus of silicone rubber was improved. Additionally, the 
mechanical properties of silicone rubber, including elasticity, would not be decreased.

We have previously prepared silicone rubber by reacting piperazine- and acryl-substituted polysiloxanes via aza-Michael reaction. ${ }^{18}$ This novel cure system is greatly advantageous because it is free of catalysts and the absence of catalyst residues in the silicone rubber. Moreover, the cure temperature is not too high. Thiol-ene reaction is also an efficient reaction, which has been used widely in the architecture of polymers. ${ }^{19,20}$ However, catalyst is necessary in the reaction. Furthermore, the reaction are initiated by UV light, which is limited by its poor permeate ability to the inner part of reaction system.

Silicone rubber cured by aza-Michael reaction exhibited excellent mechanical properties. When the piperazine group content of the base gum was increased, the modulus increased, whereas the tensile strength and elongation at break decreased. Therefore, increasing the crosslinking density can improve the modulus but reduce the elasticity. New molecular structures of base gums were designed in this study to improve the modulus and maintain other mechanical properties at a good level. Polysiloxanes containing aminopropyl or aminoethylaminopropyl groups in the side chains were synthesized. These groups can be centrally crosslinked during vulcanization through diaddition or triaddition with acryl-substituted crosslinking via azaMichael reaction. The "tension spring-type crosslinking" was formed and gave the novel silicone rubber higher modulus, compared with that of the silicone rubber prepared from piperazine-substituted polysiloxanes via monoaddition reaction. The novel silicone rubber also exhibited favorable elasticity and other mechanical properties.

\section{Experimental section}

\subsection{Materials}

The synthesis of poly[(piperazinylpropyl)methylsiloxane-codimethylsiloxane] (P1) and oligo[(acryloxypropyl)methylsiloxane-co-dimethylsiloxane] (AP-PDMS) was described detailedly in our previous article. ${ }^{18}$ Tetramethylammonium siloxanolate was synthesized according to the published procedure. ${ }^{21}$ (3-Aminopropyl)methyl-diethoxysilane and $(N-\beta-$ aminoethyl- $\gamma$-aminopropyl)methyldi-methoxylsilane were obtained as commercial products from Aladdin Co. (China) and used as received. Octamethylcyclo-tetrasiloxane $\left(\mathrm{D}_{4}\right)$, dimethyldimethoxysilane and diethoxydi-methylsilane were purchased from Qufu Wanda Chemical Co., Ltd. and distilled before use. Toluene (AR grade), magnesium sulfate (AR grade) and potassium hydroxide (AR grade) were obtained from Diamond Advanced Material of Chemical Inc. (China). The treated fumed silica (TS-530) was supplied from Cabot.

\subsection{Characterization and measurements}

${ }^{1} \mathrm{H}$ NMR, ${ }^{13} \mathrm{C}$ NMR and ${ }^{29} \mathrm{Si}$ NMR were conducted with a Bruker AVANCE 400 spectrometer at room temperature, using $\mathrm{CDCl}_{3}$ as the solvent and without tetramethylsilane as an interior label. Solid-state ${ }^{13} \mathrm{C}$ NMR were carried out on Bruker AV300 spectrometer. Fourier transform infrared spectra (FT-IR) were obtained with a Bruker TENSOR27 infrared spectrophotometer. Each spectrum was recorded by performing 32 scans, in the range of $4000-400 \mathrm{~cm}^{-1}$, with $4 \mathrm{~cm}^{-1}$ resolution. Gel Permeation Chromatography (GPC) measurements were conducted on a waters 515 liquid chromatograph (Milford, MA), using a refractive-index detector 2414. Thermogravimetric analysis (TGA) was performed on SDTQ600, from $30{ }^{\circ} \mathrm{C}$ to $800{ }^{\circ} \mathrm{C}$, with a heating rate of $10{ }^{\circ} \mathrm{C} \min ^{-1}$, under $\mathrm{N}_{2}$ atmosphere. The content of amino groups were measured by chemical titration according to HG/T 4260-2011 method. The cure curves were performed on MDR-2000 Monsanto moving-disk rheometer (Alpha Technologies). The mechanical properties of silicone rubber were obtained from a WDW-5 universal testing machine (KeXin Testing Machine Co., Ltd). The tensile testing was measured through the ASTM D 412 method, using dumb-bell shaped test specimens, at ambient temperature. The tear testing was performed according to ASTM D 624 with rightangled test specimens (QB/T 1130-1991). The hardness was determined on Shore A durometer (Laizhou Huayin Research Instruments Co., China) with ASTM D 2240 method. The crosslinking density of silicone rubber was measured by the toluene-swelling method. ${ }^{18,22}$

\subsection{Synthesis of 3-}

aminopropylheptamethylcyclotetrasiloxane $\left(\mathrm{D}_{3} \mathrm{D}^{-\mathrm{NH}_{2}}\right)$

A mix of (3-aminopropyl)methyldiethoxysilane (38.27 g, $0.2 \mathrm{~mol}$ ) and diethoxydimethylsilane $(89.33 \mathrm{~g}, 0.6 \mathrm{~mol})$ was added dropwise to the solution of toluene $(300 \mathrm{~mL})$, distilled water $(280 \mathrm{~mL})$ and $\mathrm{KOH}(4.14 \mathrm{~g})$, under stirring in the ice water bath. Then, the mixture was stirred at ambient temperature for $1.5 \mathrm{~h}$, and heated to reflux for $3 \mathrm{~h}$. When cooled to room temperature, water layer was removed. The solution was washed with water $(200 \mathrm{~mL})$ three times to remove the catalyst $\mathrm{KOH}$. Then, it was dried over $\mathrm{MgSO}_{4}$ overnight and filtered. The filtrate was concentrated in a vacuum to remove all the solvents. A colorless transparent liquid of $17.42 \mathrm{~g}$ was obtained at $94-96{ }^{\circ} \mathrm{C}$ under reduce pressure $(1 \mathrm{mmHg})$. Yield: $25 \% .{ }^{1} \mathrm{H}$ NMR $(400 \mathrm{MHz}$, $\left.\mathrm{CDCl}_{3}\right):[\delta, \mathrm{ppm}]=2.69(\mathrm{t}, 2 \mathrm{H}), 1.51(\mathrm{~m}, 2 \mathrm{H}), 1.40(\mathrm{~s}, 2 \mathrm{H}), 0.55(\mathrm{t}$, $2 \mathrm{H}), 0.11(\mathrm{~m}, 21 \mathrm{H}) .{ }^{13} \mathrm{C}$ NMR $\left(400 \mathrm{MHz}, \mathrm{CDCl}_{3}\right):[\delta, \mathrm{ppm}]=$ $44.99,27.19,14.00,0.56,-0.92 .{ }^{29} \mathrm{Si} \mathrm{NMR}\left(400 \mathrm{MHz}, \mathrm{CDCl}_{3}\right):[\delta$, $\mathrm{ppm}]=-19.39,-20.17$. ESI-MS: $\left[\mathrm{M}+\mathrm{H}^{+}\right]_{\exp }=340.1342 \mathrm{~m} / \mathrm{z}$ and $\left[\mathrm{M}+\mathrm{H}^{+}\right]_{\mathrm{calc}}=340.6915 \mathrm{~m} / \mathrm{z}$.

\subsection{Synthesis of $N$ - $\beta$-aminoethyl- $\gamma$ -} aminopropylheptamethylcyclo-tetrasiloxane $\left(\mathrm{D}_{3} \mathrm{D}^{-\mathrm{NHCH}_{2} \mathrm{CH}_{2} \mathrm{NH}_{2}}\right)$

$\mathrm{D}_{3} \mathrm{D}^{-\mathrm{NHCH}_{2} \mathrm{CH}_{2} \mathrm{NH}_{2}}$ was synthesized for the first time here. A mix of ( $N$ - $\beta$-aminoethyl- $\gamma$-aminopropyl)methyldimethoxylsilane $(41.81 \mathrm{~g}, 0.2 \mathrm{~mol})$ and dimethyldimethoxysilane $(73.07 \mathrm{~g}, 0.6$ $\mathrm{mol})$ was added dropwise to the solution of toluene $(300 \mathrm{~mL})$, distilled water $(280 \mathrm{~mL})$ and $\mathrm{KOH}(4.02 \mathrm{~g})$, under stirring in the ice water bath. Then, the mixture was stirred at ambient temperature for $1.5 \mathrm{~h}$, and heated to reflux for $3 \mathrm{~h}$. When cooled to room temperature, water layer was removed. The solution was washed with water $(200 \mathrm{~mL})$ three times to remove the catalyst $\mathrm{KOH}$. Then, it was dried over $\mathrm{MgSO}_{4}$ overnight and 
filtered. The filtrate was concentrated in a vacuum to remove all the solvents. A colorless transparent liquid of $9.78 \mathrm{~g}$ was obtained at $128-132{ }^{\circ} \mathrm{C}$ under reduce pressure $(1 \mathrm{mmHg})$. Yield: $13 \% .{ }^{1} \mathrm{H} \mathrm{NMR}\left(400 \mathrm{MHz}, \mathrm{CDCl}_{3}\right):[\delta, \mathrm{ppm}]=2.89(\mathrm{t}, 2 \mathrm{H}), 2.77(\mathrm{t}$, $2 \mathrm{H}), 2.69(\mathrm{t}, 2 \mathrm{H}), 2.43(\mathrm{~s}, 3 \mathrm{H}), 1.61(\mathrm{~m}, 2 \mathrm{H}), 0.56(\mathrm{t}, 2 \mathrm{H}), 0.10(\mathrm{~m}$, $21 \mathrm{H}) .{ }^{13} \mathrm{C}$ NMR $\left(400 \mathrm{MHz}, \mathrm{CDCl}_{3}\right):[\delta, \mathrm{ppm}]=52.61,52.30$, 41.76, 23.35, 14.39, 0.56, -0.97. ${ }^{29} \mathrm{Si} \mathrm{NMR}\left(400 \mathrm{MHz}, \mathrm{CDCl}_{3}\right):[\delta$, $\mathrm{ppm}]=-19.49,-20.29$. ESI-MS: $\left[\mathrm{M}+\mathrm{H}^{+}\right]_{\exp }=383.1756 \mathrm{~m} / z$ and $\left[\mathrm{M}+\mathrm{H}^{+}\right]_{\mathrm{calc}}=383.7593 \mathrm{~m} / \mathrm{z}$.

\subsection{Synthesis of poly[(aminopropyl)methylsiloxane-co- dimethyl-siloxane] (P2)}

$\mathrm{D}_{3} \mathrm{D}^{-\mathrm{NH}_{2}}$ (1.14 g), $\mathrm{D}_{4}(360 \mathrm{~g})$, were added to a three-neck flask equipped with a stir bar and condenser. The mixture was heated to $40{ }^{\circ} \mathrm{C}$ and the pressure in the flask was vacuumed to 1 $\mathrm{mmHg}$ to undergo a dehydration process. After $0.5 \mathrm{~h}$, tetramethylammonium siloxanolate $(4.35 \mathrm{~g}$ ) was added to the flask under dry argon atmosphere. The mixture was stirred at $80^{\circ} \mathrm{C}$ for $4 \mathrm{~h}$ and $100{ }^{\circ} \mathrm{C}$ for another $5 \mathrm{~h}$. Then, the system temperature was quickly heated to $150{ }^{\circ} \mathrm{C}$ and kept at this temperature for $0.5 \mathrm{~h}$ to remove the catalyst. Finally, by stripping of volatiles at $130-150{ }^{\circ} \mathrm{C}$ under vacuum (1 mmHg), a colorless viscous fluid product was obtained. The weight of final product is $298 \mathrm{~g}$ and the yield is $83 \%$.

\subsection{Synthesis of poly[(aminoethylaminopropyl) methylsiloxane-co-dimethylsiloxane] (P3)}

$\mathrm{D}_{3} \mathrm{D}^{-\mathrm{NHCH}_{2} \mathrm{CH}_{2} \mathrm{NH}_{2}}(1.28 \mathrm{~g}), \mathrm{D}_{4}(360 \mathrm{~g})$, were added to a three-neck flask equipped with a stir bar and condenser. The mixture was heated to $40{ }^{\circ} \mathrm{C}$ and the pressure in the flask was vacuumed to 1 $\mathrm{mmHg}$ to undergo a dehydration process. After $0.5 \mathrm{~h}$, tetramethylammonium siloxanolate $(4.38 \mathrm{~g}$ ) was added to the flask under dry argon atmosphere. The mixture was stirred at $80{ }^{\circ} \mathrm{C}$ for $4 \mathrm{~h}$ and $100{ }^{\circ} \mathrm{C}$ for another $5 \mathrm{~h}$. Then, the system temperature was quickly heated to $150{ }^{\circ} \mathrm{C}$ and kept at this temperature for $0.5 \mathrm{~h}$ to remove the catalyst. Finally, by stripping of volatiles at $130-150{ }^{\circ} \mathrm{C}$ under vacuum (1 mmHg), a colorless viscous fluid product was obtained. The weight of final product is $302 \mathrm{~g}$ and the yield is $84 \%$.

\subsection{Preparation of silicone rubber}

The mixing of all materials was performed on a two-roll mill. Firstly, base gums were encapsulated on rollers. Then, reinforcing filler (silica TS-530) was added stepwise. The weight ratio of base gums and filler was $100: 60$. This process took about 0.5 h. Finally, the crosslinker (AP-PDMS) was added. After uniform mixing, the mixture was put into a steel mold and compression molded at $120{ }^{\circ} \mathrm{C}$ under a pressure of $10 \mathrm{MPa}$ for $0.5 \mathrm{~h}$. Then, the silicone rubber was placed in an oven at high temperature for $4 \mathrm{~h}$ to accomplish curing (postcure process). The silicone rubber samples were left at room temperature for $24 \mathrm{~h}$ before testing.

\section{Results and discussion}

\subsection{P2 and P3 synthesis}

P2 and P3 were synthesized using the method similar to that used for P1; this method was described in our previous article. ${ }^{18}$

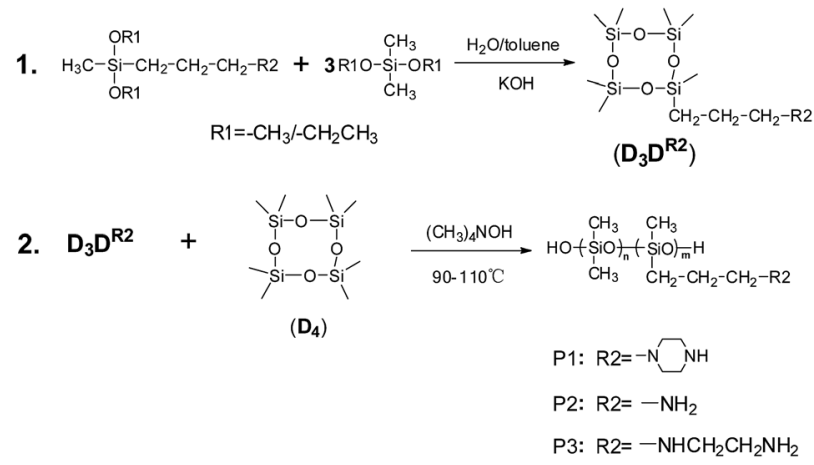

Scheme 1 Synthetic route of the three kinds of base gums.

Their general route is shown in Scheme 1. To produce $\mathrm{P} 2$ and $\mathrm{P} 3, \mathrm{D}_{3} \mathrm{D}^{-\mathrm{NH}_{2}}$ and $\mathrm{D}_{3} \mathrm{D}^{-\mathrm{NHCH}_{2} \mathrm{CH}_{2} \mathrm{NH}_{2}}$ were synthesized to be equilibration reacted with $\mathrm{D}_{4}$ using tetramethylammonium siloxanolate as a catalyst. The aminopropyl- or aminoethylaminopropyl-substituted cyclic compounds were helpful to obtain high-molecular-weight polysiloxanes. The highmolecular weight base gums were the prerequisite to obtain a prepared silicone rubber with good mechanical properties. The catalyst has the advantage of being removed easily because it was decomposed at temperatures higher than $130^{\circ} \mathrm{C}$, and the decomposition can be siphoned off in a vacuum, therefore providing a simple and easy way to synthesize high-molecularweight $\mathrm{P} 2$ and $\mathrm{P} 3$.

$\mathrm{D}_{3} \mathrm{D}^{-\mathrm{NH}_{2}}$ synthesis was reported previously. ${ }^{23,24} \mathrm{D}_{3} \mathrm{D}^{-\mathrm{NH}_{2}}$ was prepared through hydrosilylation of allylamine with heptamethylcyclotetrasiloxane in the presence of chloroplatinic acid as catalyst. The amino group on allylamine must be protected because it could poison the catalyst and cause the catalyst to lose activity. The amino group had to undergo a deprotection process after the hydrosilylation addition is completed to obtain the final product. Thus, the method is tedious. Here, we provide a simple way to produce $\mathrm{D}_{3} \mathrm{D}^{-\mathrm{NH}_{2}} \cdot \mathrm{D}_{3} \mathrm{D}^{-\mathrm{NH}_{2}}$ was synthesized by cohydrolyzing (3-aminopropyl)methyldiethoxy-silane and diethoxydimethylsilane in toluene and water at a molar ratio of $1: 3$. Hydrolysis reaction was catalyzed by potassium hydroxide. The hydrolysate consists of cyclic and linear oligomers, and pure $\mathrm{D}_{3} \mathrm{D}^{-\mathrm{NH}_{2}}$ was easily obtained through distillation at reduced pressure. Our method was simple and easy to perform, avoiding the use of expensive metal catalyst, and the tedious protection and deprotection procedure. The chemical structure of $\mathrm{D}_{3} \mathrm{D}^{-\mathrm{NH}_{2}}$ was characterized through nuclear magnetic resonance (NMR) and mass spectroscopy (ESI $\dagger$ ). The signal positions in ${ }^{1} \mathrm{H}$ NMR spectrum exactly corresponded to the structure of $\mathrm{D}_{3} \mathrm{D}^{-\mathrm{NH}_{2}}$. In addition, the ratio of each signal integration conformed with the ratio of protons on $\mathrm{D}_{3} \mathrm{D}^{-\mathrm{NH}_{2}}$. The signals of $\mathrm{Si}-\mathrm{CH}_{3}$ and $\mathrm{Si}-\mathrm{CH}_{2}$ were at $0.11 \mathrm{ppm}$ and $0.55 \mathrm{ppm}$, and the ratio of their integration was close to $21: 2$. That is, the ratio of $\mathrm{Si}-\mathrm{CH}_{3}$ and the aminopropyl group was $7: 1$. $\left[\mathrm{M}+\mathrm{H}^{+}\right]_{\exp }$ was shown to have a value of 340.1342 in the mass spectrum. These results indicated that $\mathrm{D}_{3} \mathrm{D}^{-\mathrm{NH}_{2}}$ has one aminopropyl group, seven $-\mathrm{CH}_{3}$, and four silicon atoms. $\mathrm{D}_{3} \mathrm{D}^{-\mathrm{NH}_{2}}$ structure was confirmed through ${ }^{13} \mathrm{C}$ NMR and ${ }^{29} \mathrm{Si}$ NMR spectra. Each signal 
in the ${ }^{13} \mathrm{C}$ NMR spectrum was consistent with the position of carbon atoms on $\mathrm{D}_{3} \mathrm{D}^{-\mathrm{NH}_{2}}$, and each signal in the ${ }^{29} \mathrm{Si} \mathrm{NMR}$ spectrum corresponded to the position of silicon atoms on $\mathrm{D}_{3} \mathrm{D}^{-\mathrm{NH}_{2}}$. These results show that $\mathrm{D}_{3} \mathrm{D}^{-\mathrm{NH}_{2}}$ was successfully prepared.

$\mathrm{D}_{3} \mathrm{D}^{-\mathrm{NHCH}_{2} \mathrm{CH}_{2} \mathrm{NH}_{2}}$ was synthesized for the first time in this study. The synthetic route of $\mathrm{D}_{3} \mathrm{D}^{-\mathrm{NHCH}_{2} \mathrm{CH}_{2} \mathrm{NH}_{2}}$ was similar to that of $\mathrm{D}_{3} \mathrm{D}^{-\mathrm{NH}_{2}}$. The chemical structure of $\mathrm{D}_{3} \mathrm{D}^{-\mathrm{NHCH}_{2} \mathrm{CH}_{2} \mathrm{NH}_{2}}$ was also confirmed through NMR and mass spectroscopy (ESI $\dagger$ ). The analysis was similar to the section above. The results from several research techniques, including ${ }^{1} \mathrm{H} \mathrm{NMR},{ }^{13} \mathrm{C} \mathrm{NMR},{ }^{29} \mathrm{Si}$ $\mathrm{NMR}$, and mass spectra, showed that $\mathrm{D}_{3} \mathrm{D}^{-\mathrm{NHCH}_{2} \mathrm{CH}_{2} \mathrm{NH}_{2}}$ was successfully obtained.

\subsection{Silicone rubber preparation}

Novel silicone rubber with high modulus was prepared with P2 or P3 as the base gums, oligo[(acryloxypropyl)methylsiloxane-codimethylsiloxane] (AP-PDMS) as the crosslinker, and silica (TS530) as the reinforcing filler. These materials were cured through catalyst-free aza-Michael reaction. Primary amines have the capability to react with two equivalents of acceptor. ${ }^{25}$ Thus, diaddition occurred between aminopropyl groups on P2 with an enough amount of acryl groups on AP-PDMS during vulcanization. Every two crosslinking points were converged on each side chain of the base polysiloxanes, which looks like tensile spring [Scheme 2(a)]. Thus, this kind of crosslinking was called "tension spring-type crosslinking". This crosslinking differed considerably from the common type of crosslinking, which has irregularly distributed crosslinking points. The junction concentration on the main chain of tension springtype crosslinking gave the silicone rubber high modulus and favorable elasticity. The aminoethylaminopropyl groups in the side chains of P3 were crosslinked via triaddition, as shown in Scheme 2(b), also forming the tension spring-type crosslinking.

In general, increasing the crosslinking density can increase the rubber modulus. However, if the crosslinking density is too high, the average molecular weight between crosslinking points $\left(M_{\mathrm{c}}\right)$ is decreased, and the rubber flexibility also becomes poor.

(a)
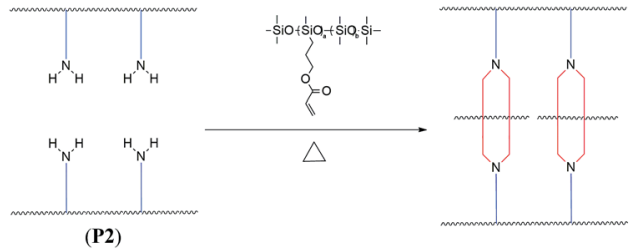

(b)

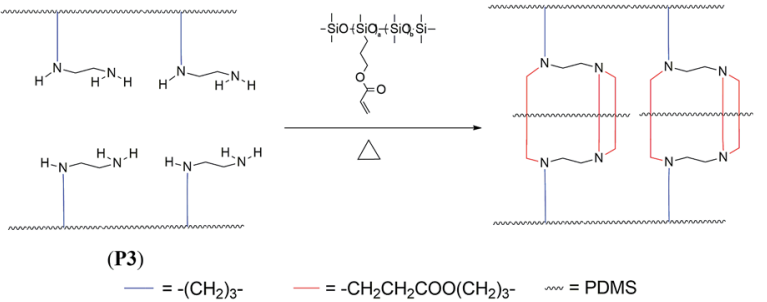

Scheme 2 Crosslinking mechanism of the silicone rubber with high modulus.
High-crosslinking density also limited the activities of the chain segments, and this is not beneficial to disperse the stress. High stress may easily lead to the rupture of chain segments, ${ }^{16}$ thus resulting to poor mechanical properties of the rubber. The tension spring-type crosslinking can solve this problem. Every two or three crosslinking points focused on each side chain of base polysiloxanes. The regular concentration of crosslinking points will not decrease $M_{\mathrm{c}}$ when the crosslinking density is increased. Thus, this type of crosslinking gives the silicone rubber high modulus and good flexibility and mechanical properties.

The crosslinking mechanism was confirmed through ${ }^{13} \mathrm{C}$ solid-state NMR and Fourier transform infrared (FT-IR) spectroscopy. P2 or P3 with high amino group content was utilized so they can be easily detected by the instruments. Comparison of ${ }^{13} \mathrm{C}$ NMR spectra of P2, AP-PDMS, and their cross-linked elastomeric material is shown in Fig. 1. The molar ratio of aminopropyl/acryl was $1: 2$. The two signals at $127.8 \mathrm{ppm}$ and $128.9 \mathrm{ppm}$ (label $\mathrm{m}, \mathrm{l}$ ), which were assigned to ethylenic carbons on AP-PDMS, disappeared. This shows that acryl groups on APPDMS were completely consumed after Michael addition reaction. The new generated group $-\mathrm{N}-\mathrm{CH}_{2}-\mathrm{CH}_{2}-\mathrm{COO}-$ was detected in the elastomer. The new signals at $49.5 \mathrm{ppm}$ and $32.7 \mathrm{ppm}$ (label n, o) was attributed to the carbons on $-\mathrm{N}-\mathrm{CH}_{2}-\mathrm{CH}_{2}-\mathrm{COO}-$ . The signal at $164.7 \mathrm{ppm}$ (label $\mathrm{k}$ ), which was assigned to carbonyl carbon on AP-PDMS, shifted to 171.4 ppm (label $\mathrm{k}^{\prime}$ ) after crosslinking. In addition, the signal at $45.3 \mathrm{ppm}$ (label e), which was attributed to carbon on $\mathrm{NH}_{2}-\mathrm{CH}_{2}-\mathrm{CH}_{2}-\mathrm{CH}_{2}-$ of P2, shifted to $52.7 \mathrm{ppm}$ (label $\mathrm{e}^{\prime}$ ) after the addition reaction occurred. These results showed that the elastomer was crosslinked via aza-Michael reaction. Comparison of FT-IR spectra is shown in Fig. 2. As shown, the amino group on P2 was not present in the crosslinked elastomer. If only monoaddition occurred, secondary amine was formed and can be detected. However, no sign of secondary amine was found in the FT-IR spectrum of the elastomer. Thus, diaddition occurred, and the amino groups on P2 were completely consumed to form tertiary amines. The structure of diadduct was consistent

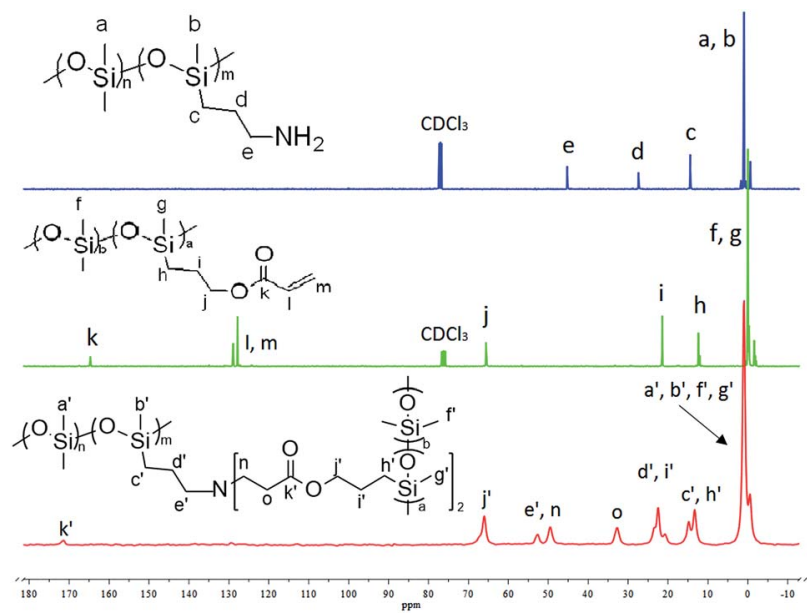

Fig. 1 Comparison ${ }^{13} \mathrm{C}$ NMR spectra of P2, AP-PDMS (in $\mathrm{CDCl}_{3}$ ) and their cross-linked elastomer (solid-state). 


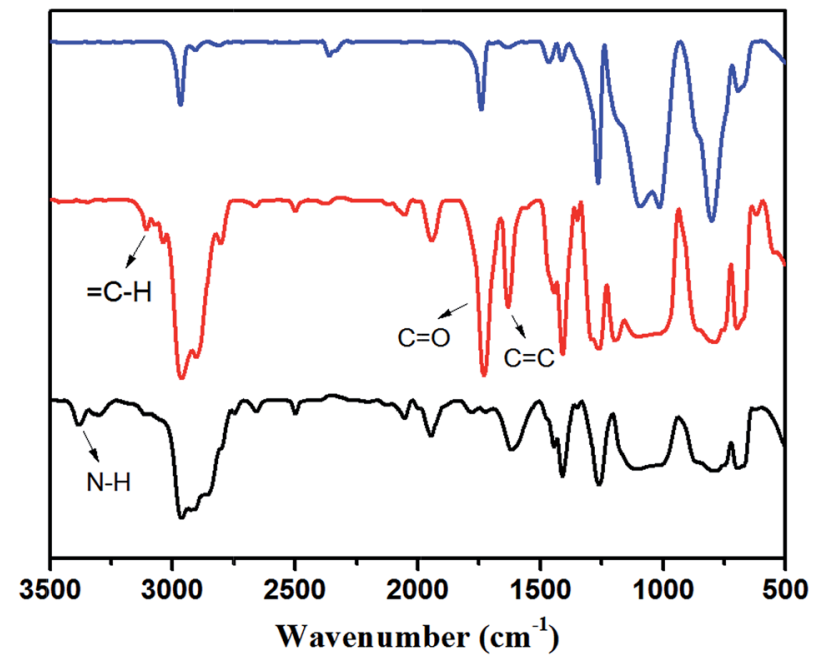

Fig. 2 FT-IR spectra of P2 (bottom curve), AP-PDMS (middle curve) and their cross-linked elastomer (top curve).

with the ${ }^{13} \mathrm{C}$ NMR spectra above. Thus, P2 was successfully crosslinked through the aza-Michael reaction of the aminopropyl and acryl groups via diaddition.

Comparison of ${ }^{13} \mathrm{C}$ NMR spectra of P3, AP-PDMS, and their crosslinked elastomer is shown in Fig. 3. The molar ratio of aminoethylaminopropyl/acryl was $1: 3$. The two signals at 127.8 and $128.9 \mathrm{ppm}$ (label $\mathrm{n}, \mathrm{o}$ ), which were attributed to ethylenic carbons on AP-PDMS, were not present in the elastomer. The new group $-\mathrm{N}-\mathrm{CH}_{2}-\mathrm{CH}_{2}-\mathrm{COO}-$ can be seen from the presence of two new signals at $49.9 \mathrm{ppm}$ and $32.8 \mathrm{ppm}$ (label p, q). The signal at $41.9 \mathrm{ppm}$ (label e), which was assigned to carbon on $-\mathrm{NH}-\mathrm{CH}_{2}-\mathrm{CH}_{2}-\mathrm{CH}_{2}-$ of P3, shifted to $57.7 \mathrm{ppm}$ (label e') after the addition reaction occurred. The signals at $53.0 \mathrm{ppm}$ and

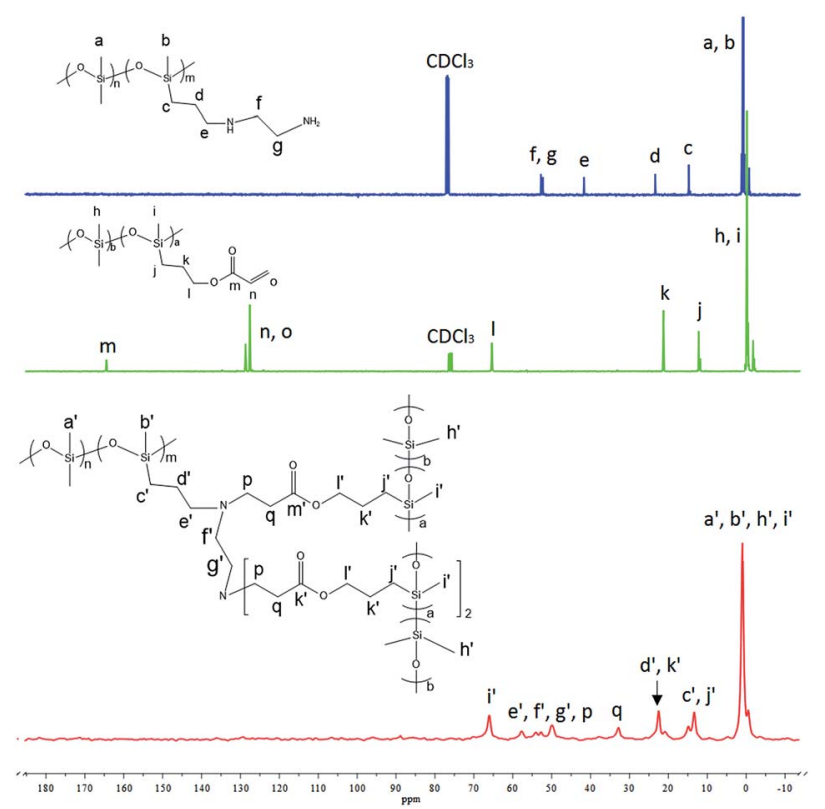

Fig. 3 Comparison ${ }^{13} \mathrm{C}$ NMR spectra of P3, AP-PDMS (in $\mathrm{CDCl}_{3}$ ) and their cross-linked elastomer (solid-state).

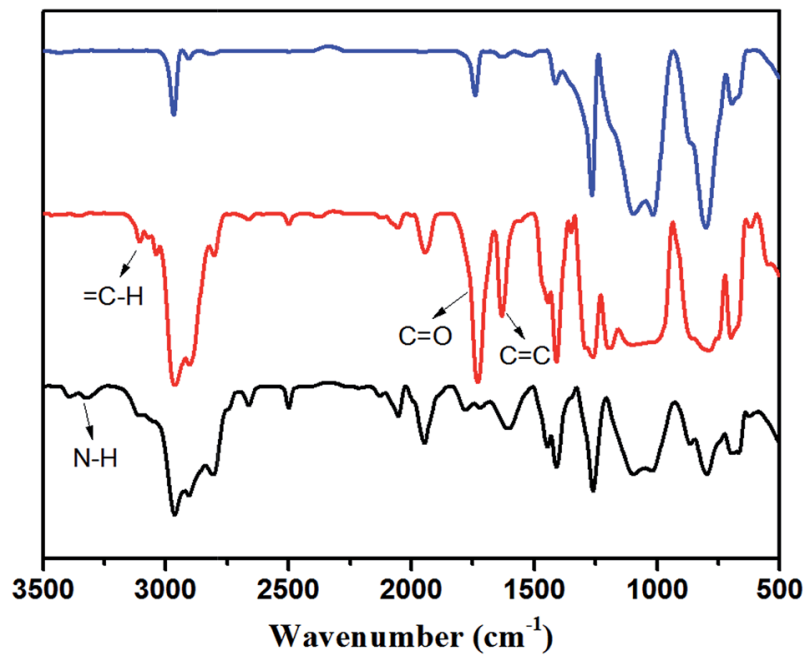

Fig. 4 FT-IR spectra of P3 (bottom curve), AP-PDMS (middle curve) and their cross-linked elastomer (top curve).

$52.5 \mathrm{ppm}$ (label $\mathrm{f}, \mathrm{g}$ ), which were attributed to carbons on $\mathrm{NH}_{2}-$ $\mathrm{CH}_{2}-\mathrm{CH}_{2}-\mathrm{NH}-$, also shifted to $54.0 \mathrm{ppm}$ and $52.7 \mathrm{ppm}$ (label f', $\left.\mathrm{g}^{\prime}\right)$ in the elastomer. These results indicated that P3 was crosslinked with AP-PDMS via aza-Michael reaction. The comparison of FT-IR spectra of P3, AP-PDMS, and their elastomer in Fig. 4 shows that amino groups on $\mathrm{P} 3$, including primary amine (aminopropyl group) and secondary amine (aminoethyl group), were completely consumed after crosslinking. That is, diaddition occurred in primary amine and monoaddition occurred in secondary amine. Thus, P3 was crosslinked through the azaMichael reaction of aminoethylaminopropyl and acryl groups via triaddition.

\subsection{Cure-curve analysis}

Cure-curve analysis, which is widely used to measure the rubber's curing characteristics, was performed on a moving-die rheometer. The rheometer measures the torque as a function of curing time when the silicone rubber cures. The torque value is

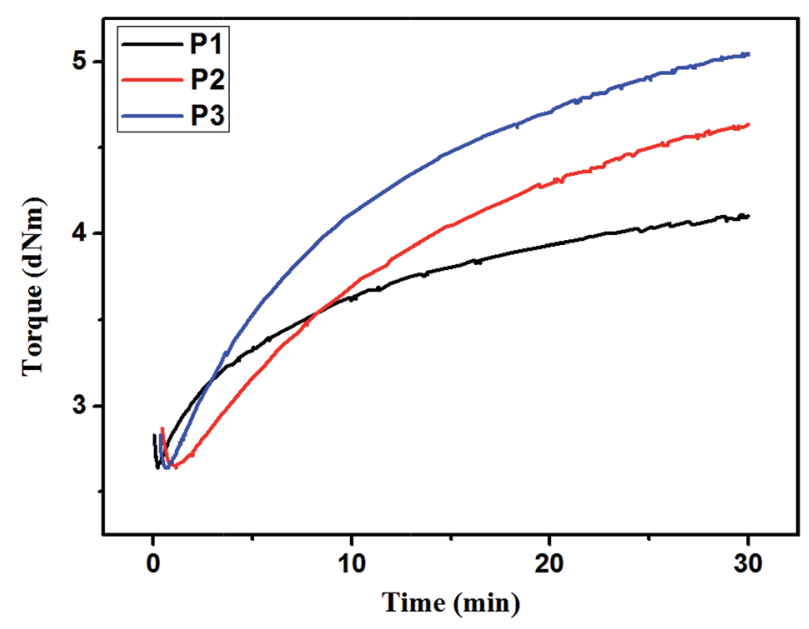

Fig. 5 Cure-curve of the silicone rubber at $120^{\circ} \mathrm{C}$. 
directly related to crosslink density of the rubber network. ${ }^{26,27}$ The cure curve of $\mathrm{P} 1, \mathrm{P} 2$, and $\mathrm{P} 3$ at $120^{\circ} \mathrm{C}$ is shown in Fig. 5. In the first stage, the torque of all samples decreased because of the softening effect of high temperature. This stage, which is also called the scorch period or the induction stage, is very short, and no crosslinking is assumed to occur during this stage. The torque increased abruptly in the second stage. Crosslinking reaction and network formation occurred during this stage. The increasing rate of $\mathrm{P} 1$ torque is the fastest compared with that of other torque; the order is P1 > P3 > P2, and this can be attributed to the different reactivities of amino groups on the three kinds of base gums. As shown from the cure curve, the reactivity sequence of the three types of amino groups was piperazine $>$ aminoethylaminopropyl $>$ aminopropyl. This finding was consistent with previously reported result. ${ }^{28,29}$ In the final stage, crosslinking reaction was mostly completed, and the torque remained constant. The order of the final torque value was $\mathrm{P} 3>\mathrm{P} 2>\mathrm{P} 1$, and the torque value was proportional to the crosslinking density of the rubber. The three kinds of base gums had the same content of side chains. However, P3 was crosslinked via triaddition; thus, its crosslinking density is the largest among the three. Meanwhile, P2 was crosslinked via diaddition; thus, its crosslinking density was lower than that of P3. P1 was crosslinked via monoaddition, thus, its crosslinking density was the smallest among the three. These results indicated that the base gums were cured and the rubber network formed at $120{ }^{\circ} \mathrm{C}$. In addition, P2 or P3 had high crosslinking density because of multi-addition reaction.

\subsection{Postcure condition}

The aim of postcure was to complete the crosslinking reaction and stabilize the performance of the vulcanizates. In the firststage cure, the base gums, crosslinker, and filler were mixed uniformly and cured at $120{ }^{\circ} \mathrm{C}$ for $0.5 \mathrm{~h}$ under a pressure of $10 \mathrm{MPa}$. Then, the silicone rubber was placed in an oven for postcure process. In $\mathrm{P} 1$, the optimum postcure conditions were $160{ }^{\circ} \mathrm{C}$ for $4 \mathrm{~h}^{18}$ However, the postcure conditions for P2 or P3 need to be researched because of the low reactivity of their amino groups. Thus, the postcure temperature was increased to accelerate the vulcanization process. The effects of different temperatures on the mechanical properties of cured P2 are

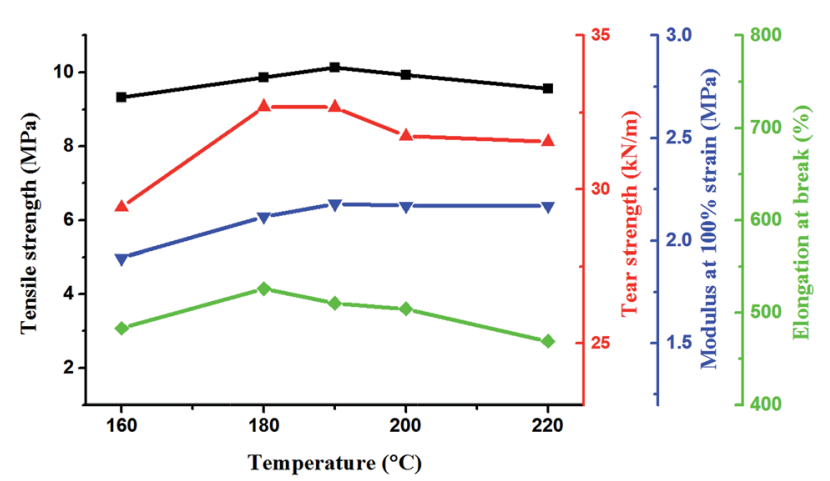

Fig. 6 The effects of different postcure temperatures on the mechanical properties of cured P2. shown in Fig. 6. The postcure time was $4 \mathrm{~h}$. The mechanical properties, including tensile strength, tear strength, modulus at $100 \%$ strain, and elongation at break, were all improved with increasing postcure temperature. However, the mechanical properties decreased when the temperature was higher than $190{ }^{\circ} \mathrm{C}$, possibly because of aging. The aminopropyl groups on P2 were easily reacted with one equivalent of acryl groups to form secondary amines via aza-Michael reaction. However, to continue reacting with acryl groups was difficult for the formed amines because of the high steric hindrance. Thus, increasing the postcure temperature to accelerate the diaddition reaction was necessary. With the increase of temperature, the diaddition reaction was close to completion, the crosslinking density increased, and the modulus was also improved. When the temperature was $190{ }^{\circ} \mathrm{C}$, the modulus at $100 \%$ strain reached maximum value, as shown in Fig. 6 . The crosslinking reaction was completed. This result illustrated that diaddition was helpful to improve the modulus of silicone rubber. The optimum postcure conditions of $\mathrm{P} 2$ were determined as $190{ }^{\circ} \mathrm{C}$ for $4 \mathrm{~h}$.

The effects of postcure temperatures on the mechanical properties of cured P3 are shown in Fig. 7. The mechanical properties were all improved with increasing postcure temperature. When the temperature was $190{ }^{\circ} \mathrm{C}$, the silicone rubber presents optimal mechanical properties. Therefore, the postcure conditions of $\mathrm{P} 3$ were similar with that of $\mathrm{P} 2$, that is, $190^{\circ} \mathrm{C}$ for $4 \mathrm{~h}$. This result can be explained by the reactivity of the amino group. Reacting the primary amine and secondary amine on aminoethylaminopropyl groups of P3 with one equivalent of acceptor to form secondary amines and tertiary amines was easy. However, the formed secondary amines had difficulty to continue reacting with acceptor because of the increased steric hindrance. ${ }^{30}$ This situation was similar to $\mathrm{P} 2$, and high postcure temperatures were adopted to complete the crosslinking reaction. Thus, the postcure conditions which were $190{ }^{\circ} \mathrm{C}$ for $4 \mathrm{~h}$, were the same for $\mathrm{P} 2$ and $\mathrm{P} 3$.

\subsection{Proportion of crosslinkers}

The effects of the amount of crosslinkers (AP-PDMS) used on mechanical properties of cured P2 were investigated. The optimum proportion of crosslinkers was found to be

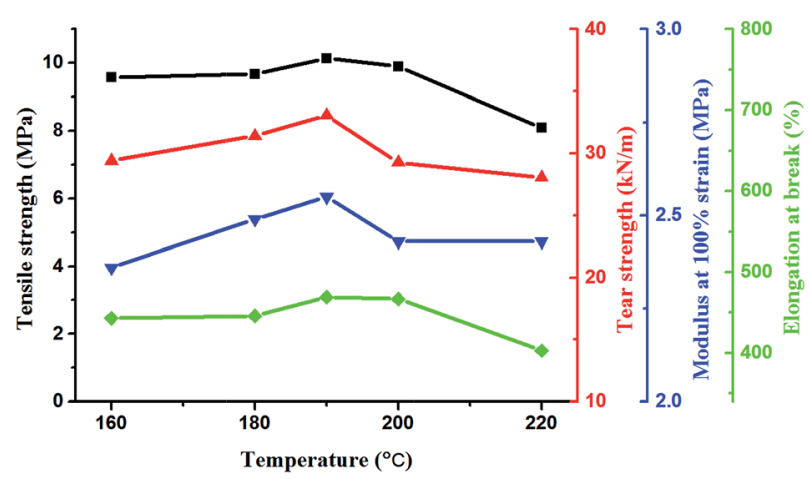

Fig. 7 The effects of different postcure temperatures on the mechanical properties of cured P3. 
Table 1 The effects of the ratio of crosslinkers on mechanical properties of cured P2

\begin{tabular}{lccccc}
\hline $\begin{array}{l}-\mathrm{NH}_{2} / \mathrm{COCH}=\mathrm{CH}_{2} \\
\left(\mathrm{~mol} \mathrm{~mol}^{-1} \text { ) }\right.\end{array}$ & $1: 1.5$ & $1: 2$ & $1: 2.25$ & $1: 2.5$ & $1: 3$ \\
$\begin{array}{l}\text { Young's modulus } \\
\text { (MPa) }\end{array}$ & 2.86 & 3.47 & 4.51 & 2.86 & 3.64 \\
$\begin{array}{l}\text { Modulus at } 100 \% \text { strain } \\
\text { (MPa) }\end{array}$ & 1.82 & 1.96 & 2.18 & 1.86 & 1.98 \\
$\begin{array}{l}\text { Tensile strength } \\
\text { (MPa) }\end{array}$ & 9.40 & 10.05 & 10.08 & 10.14 & 9.71 \\
$\begin{array}{l}\text { Tear strength } \\
\text { (kN m }{ }^{-1} \text { ) }\end{array}$ & 26.50 & 29.69 & 32.67 & 27.46 & 32.79 \\
$\begin{array}{l}\text { Elongation at } \\
\text { break (\%) }\end{array}$ & 488 & 509 & 510 & 507 & 488 \\
$\begin{array}{l}\text { Hardness } \\
\text { (Shore A) }\end{array}$ & 63 & 64 & 65 & 63 & 65 \\
& & & & &
\end{tabular}

aminopropyl/acryl $\left(\mathrm{mol} \mathrm{mol}^{-1}\right)=1: 2.25$, as shown in Table 1 . In this case, the silicone rubber presented the best mechanical properties, with tensile strength and tear strength reaching $10.08 \mathrm{MPa}$ and $32.67 \mathrm{kN} \mathrm{m}^{-1}$. In addition, the modulus at $100 \%$ strain reached the maximum value of $2.18 \mathrm{MPa}$. When the ratio of crosslinkers used decreased, such as aminopropyl/acryl (mol $\left.\mathrm{mol}^{-1}\right)=1: 1.5$, the amount of crosslinkers is not sufficient, portions of the base gums were crosslinked through monoaddition instead of diaddition; thus the modulus at $100 \%$ strain decreased, and the mechanical properties were poor. When the ratio of crosslinkers increased, such as aminopropyl/acryl (mol $\mathrm{mol}^{-1}$ ) $=1: 3$, parts of the base gums went through chain extension instead of being cured, reducing the mechanical properties. In conclusion, aminopropyl/acryl $\left(\mathrm{mol} \mathrm{mol}^{-1}\right)=$ $1: 2.25$ was the optimum ratio of crosslinkers used in $\mathrm{P} 2$.

The effects of the proportion of crosslinkers on mechanical properties of cured P3 are shown in Table 2. As can be seen from the data, silicone rubber exhibited good mechanical properties when aminoethylaminopropyl/acryl $\left(\mathrm{mol} \mathrm{mol}^{-1}\right)=1: 3.75$. The tensile strength was $10.14 \mathrm{MPa}$, the tear strength was $33.08 \mathrm{kN}$ $\mathrm{m}^{-1}$, and the modulus at $100 \%$ strain was $2.55 \mathrm{MPa}$. When the amount of crosslinkers decreased, such as aminoethylaminopropyl/acryl $\left(\mathrm{mol} \mathrm{mol}^{-1}\right)=1: 3$, portions of P3 were not cured via triaddition, and the modulus at $100 \%$ strain decreased. When excessive crosslinkers were used, such as aminoethylaminopropyl/ acryl $\left(\mathrm{mol} \mathrm{mol}^{-1}\right)=1: 4.5$, some of P3 underwent chain extension, and the mechanical properties were not satisfactory. In

Table 2 The effects of the ratio of crosslinkers on mechanical properties of cured P3

$\begin{array}{llllll}-\mathrm{NHCH}_{2} \mathrm{CH}_{2} \mathrm{NH}_{2} /-\mathrm{COCH}=\mathrm{CH}_{2} & 1: 3 & 1: 3.5 & 1: 3.75 & 1: 4 & 1: 4.5 \\ \left(\mathrm{~mol} \mathrm{~mol}^{-1}\right) & & & & & \\ \text { Young's modulus (MPa) } & 3.51 & 3.38 & 4.27 & 3.17 & 2.74 \\ \text { Modulus at 100\% strain (MPa) } & 2.21 & 2.17 & 2.55 & 2.22 & 1.96 \\ \text { Tensile strength (MPa) } & 8.26 & 9.24 & 10.14 & 9.53 & 9.46 \\ \text { Tear strength (kN m} & -1) \\ \text { Elongation at break (\%) } & 27.14 & 29.26 & 33.08 & 28.81 & 28.62 \\ \text { Hardness (Shore A) } & 411 & 434 & 469 & 454 & 460 \\ & 64 & 64 & 65 & 64 & 64\end{array}$

summary, the optimum ratio of crosslinkers used in P3 was aminoethylaminopropyl/acryl $\left(\mathrm{mol} \mathrm{mol}^{-1}\right)=1: 3.75$.

\subsection{Mechanical properties}

The molecular characterization of the base gums is listed in Table 3. Their molecular weight was very close according to gel permeation chromatography measurement. P1, which was reported in our previous article ${ }^{\mathbf{1 8}}$ is presented here for comparison with P2 and P3. The mechanical properties of silicone rubber prepared from these base gums are shown in Fig. 8 and summarized in detail in Table 4 . The $\mathrm{N}-\mathrm{H}$ contents of $\mathrm{P} 2$ and $\mathrm{P} 1-$ 0.13 were $0.14 \mathrm{~mol} \%$ and $0.13 \mathrm{~mol} \%$. The $\mathrm{N}-\mathrm{H}$ contents were very close and can react with the corresponding equivalents of acryl groups to form the similar crosslinking density. This was reflected in the almost same modulus of cured P2 and P3 at $100 \%$ strain. However, their flexibility is different; the elongation at break for $\mathrm{P} 1-0.13$ was $422 \%$ and was $510 \%$ for $\mathrm{P} 2$. This was because P2 was cured via tension spring-type crosslinking. Diaddition of aminopropyl groups enabled every two crosslinking points to focus on each side chain of P2. The concentration of crosslinking points increased $M_{\mathrm{c}}$, and the silicone rubber had good elasticity and satisfactory mechanical properties. This was proven by the toluene-swelling measurement, which showed that cured P2 has larger $M_{\mathrm{c}}$ than cured P1-0.13 (Table 4).

Table 3 Molecular characterization of the base gums

\begin{tabular}{llllll}
\hline Sample & $\begin{array}{l}\text { Base } \\
\text { gum }\end{array}$ & $\begin{array}{l}M_{\mathrm{w}}{ }^{a} \\
\left(10^{4}\right)\end{array}$ & PDI $^{a}$ & $\begin{array}{l}\text { N-H contents } \\
(\mathrm{mol} \%)\end{array}$ & $\begin{array}{l}\text { Side chains } \\
\text { contents }^{c}(\mathrm{~mol} \%)\end{array}$ \\
\hline P1-0.07 & P1 & 29.28 & 1.78 & 0.07 & 0.07 \\
P1-0.13 & P1 & 32.98 & 1.80 & 0.13 & 0.13 \\
P1-0.24 & P1 & 27.95 & 1.81 & 0.24 & 0.24 \\
P2 & P2 & 28.67 & 1.83 & 0.14 & 0.07 \\
P3 & P2 & 27.17 & 1.76 & 0.21 & 0.07
\end{tabular}

${ }^{a}$ Determined by GPC. ${ }^{b}$ Determined by chemical titration. ${ }^{c}$ Calculated from the result of chemical titration.

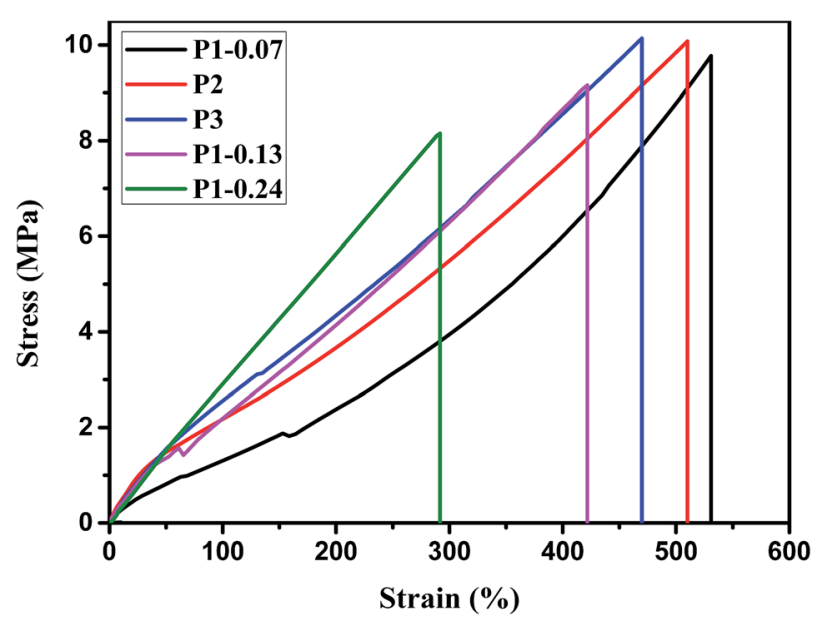

Fig. 8 Stress-strain curves of silicone rubber. 
Table 4 Summary of mechanical properties of the silicone rubber

\begin{tabular}{|c|c|c|c|c|c|}
\hline Sample & P1-0.07 & P1-0.13 & P1-0.24 & P2 & P3 \\
\hline Young's modulus (MPa) & 2.69 & 3.57 & 3.84 & 4.51 & 4.27 \\
\hline $\begin{array}{l}\text { Modulus at } 100 \% \\
\text { strain (MPa) }\end{array}$ & 1.31 & 2.19 & 2.91 & 2.18 & 2.55 \\
\hline Tensile strength (MPa) & 9.77 & 9.15 & 8.15 & 10.08 & 10.14 \\
\hline Tear strength $\left(\mathrm{kN} \mathrm{m}^{-1}\right)$ & 29.89 & 31.72 & 32.26 & 32.67 & 33.08 \\
\hline Elongation at break (\%) & 531 & 422 & 292 & 510 & 469 \\
\hline Hardness (Shore A) & 61 & 64 & 65 & 65 & 65 \\
\hline$M_{\mathrm{c}}\left(\mathrm{g} \mathrm{mol}^{-1}\right)$ & 7852 & 6337 & 4668 & 7219 & 6594 \\
\hline
\end{tabular}

The N-H contents of P3 were close to that of P1-0.24, and their modulus at $100 \%$ strain was also close. However, the elongation at break of cured P3 and P1-0.24 was different, and the gap was bigger than that of P2 and P1-0.13 because P3 was crosslinked via triaddition reaction, and more crosslinking points focused on the side chains. Thus, $M_{\mathrm{c}}$ increased as shown in Table 4. Therefore, the strong effect of concentrating of crosslinking points gave the silicone rubber of $\mathrm{P} 3$ high flexibility.

P1-0.07, P2, and P3 had almost the same content of side chains, and the elongation at break of their silicone rubber was close. However, the silicone rubber of P2 and P3 had high modulus at $100 \%$ strain because P2 and P3 were cured via tension spring-type crosslinking through multi-addition reaction, whereas P1-0.07 was crosslinked through monoaddition. The increased crosslinking density improved the modulus of cured P2 and P3. In addition, the modulus of cured P3 was higher than that of P2 because P3 was cured through triaddition and more crosslinking points formed. In summary, tension springtype crosslinking can improve the modulus of silicone rubber.

\section{Conclusion}

Novel silicone rubbers with high modulus were successfully prepared through catalyst-free aza-Michael reaction via tension spring-type crosslinking. The regular concentration of crosslinking points on the side chains of base gums increased the $M_{\mathrm{c}}$. The modulus at $100 \%$ strain increased from $1.31 \mathrm{MPa}$ of cured P1 to 2.18 MPa of cured P2 and 2.55 MPa of cured P3. Moreover, the obtained silicone rubbers maintained the high flexibility and good mechanical properties. Overall, this tension springtype crosslinking shows a great advantage in improving the modulus of silicone rubber.

\section{Acknowledgements}

We thank the National Natural Science Foundation of China (No. 21274080, 21204043 and 21502105), Shandong special fund for independent innovation and achievements transformation (No. 2014ZZCX01101) and the National Science Foundation of Shandong Province (ZR2015BQ008) for financial support.

\section{References}

1 M. Amjadi, K.-U. Kyung, I. Park and M. Sitti, Adv. Funct. Mater., 2016, 26, 1678-1698.
2 B. Li, S. Chen and J. Zhang, Polym. Chem., 2012, 3, 23662376.

3 T. Ogoshi, T. Fujiwara, M. Bertolucci, G. Galli, E. Chiellini, Y. Chujo and K. J. Wynne, J. Am. Chem. Soc., 2004, 126, 12284-12285.

4 R. Pelrine, R. Kornbluh, Q. Pei and J. Joseph, Science, 2000, 287, 836-839.

5 C. G. Zimmermann, MRS Bull., 2010, 35, 48-54.

6 S. Risse, B. Kussmaul, H. Kruger and G. Kofod, RSC Adv., 2012, 2, 9029-9035.

7 R. Sandén, Polym. Test., 2002, 21, 61-64.

8 A. M. Ragheb, M. A. Brook and M. Hrynyk, Biomaterials, 2005, 26, 1653-1664.

9 B. M. Holzapfel, J. C. Reichert, J.-T. Schantz, U. Gbureck, L. Rackwitz, U. Nöth, F. Jakob, M. Rudert, J. Groll and D. W. Hutmacher, Adv. Drug Delivery Rev., 2013, 65, 581-603. 10 D. R. Paul and J. E. Mark, Prog. Polym. Sci., 2010, 35, 893-901. 11 J. E. Mark, R. Abou-Hussein, T. Z. Sen and A. Kloczkowski, Polymer, 2005, 46, 8894-8904.

12 J. A. Marinik, US Pat., 4052357, 1977.

13 O. Franssen and A. Widmayr, Rubber World, 2011, 244, 2730.

14 L. Sereda, L. L. Y. Visconte, R. C. R. Nunes, C. R. G. Furtado and E. Riande, J. Appl. Polym. Sci., 2003, 90, 421-429.

15 Q. Xu, M. Pang, L. Zhu, Y. Zhang and S. Feng, Mater. Des., 2010, 31, 4083-4087.

16 L. R. G. Treloar, The Physics of Rubber Elasticity, Clarendon, Oxford, UK, 3rd edn, 1975.

17 S. Zhao and S. Feng, J. Appl. Polym. Sci., 2002, 83, 3123-3127. 18 L. Feng, L. Zhou and S. Feng, RSC Adv., 2016, 6, 111648111656.

19 A. H. Soeriyadi, G. Z. Li, S. Slavin, M. W. Jones, C. M. Amos, C. R. Becer, M. R. Whittaker, D. M. Haddleton, C. Boyer and T. P. Davis, Polym. Chem., 2011, 2, 815-822.

$20 \mathrm{~J} . \mathrm{Xu}$ and C. Boyer, Macromolecules, 2015, 48, 520-529.

21 J. R. Babu, G. Sinai-Zingde and J. S. Riffle, J. Polym. Sci., Part A: Polym. Chem., 1993, 31, 1645-1651.

22 S. Diao, S. Zhang, Z. Yang, S. Feng, C. Zhang, Z. Wang and G. Wang, J. Appl. Polym. Sci., 2011, 120, 2440-2447.

23 Z. Du and C. Zhou, Polym. Commun., 1984, 1, 277-282.

24 M. A. Buese and B. A. Janeiro, US Pat., 5892084, 1998.

25 B. D. Mather, K. Viswanathan, K. M. Miller and T. E. Long, Prog. Polym. Sci., 2006, 31, 487-531.

26 S. Rabiei and A. Shojaei, Eur. Polym. J., 2016, 81, 98-113.

27 P. Zhang, F. Zhao, Y. Yuan, X. Shi and S. Zhao, Polymer, 2010, 51, 257-263.

28 D. C. Wu, X. J. Loh, Y. L. Wu, C. L. Lay and Y. Liu, J. Am. Chem. Soc., 2010, 132, 15140-15143.

29 D. C. Wu, Y. Liu, L. Chen, C. B. He, T. S. Chung and S. H. Goh, Macromolecules, 2005, 38, 5519-5525.

30 D. C. Wu, Y. Liu, C. B. He, T. S. Chung and S. H. Goh, Macromolecules, 2004, 37, 6763-6770. 